\title{
Constitutional amendments and revision of the Constitution of the Russian Federation: features of the 2020 procedure
}

\author{
S. P. Kazankov ${ }^{1}$
}

${ }^{1}$ P. G. Demidov Yaroslavl State University, 14 Sovetskaya str., Yaroslavl 150003, Russian Federation

DOI: $10.18255 / 1996-5648-2021-2-232-241$

Research article

Full text in Russian

The article discusses theissue of the procedure for changing the Constitution of the Russian Federation. Examples of norms of foreign constitutions are given, which constitutionalists recognize as rigid constitutions in the order of their amendment. The ways of changing the Constitution of the Russian Federation are considered: revision, adoption of amendments, amendment of Art. 65Identified problems such as the form of the amendment to the Constitution, the moment of entry into force of the amendment, the introduction by the Law of the Russian Federation on the amendment to the Constitution of the Russian Federation of 2020 a nationwide vote as an additional condition for the entry into force of the amendment, as well as additional powers of the Constitutional Court of the Russian Federation to verify compliance with Chapters 1, 2 and 9 of the Constitution of the Russian Federation of the provisions of the Law of the Russian Federation on the amendment to the Constitution of the Russian Federation that have not entered into force, as well as the procedure for the entry into force of Art. 1 of the Amendment Act. The critical notes are offered. In particular, the author comes to the conclusion that the approval of the constitutional amendment by the parliaments of the constituent entities of the Russian Federation is not a moment, but a condition for its entry into force, therefore, the law on the amendment cannot introduce additional conditions for the entry into force of constitutional amendments, since this leads to a violation requirements of Art. 136 of the Constitution, which cannot be amended by the federal parliament in the manner prescribed by chapter 9 of the Constitution.

Keywords: revision of the Constitution; adoption of an amendment to the Constitution; the law on an amendment

\section{INFORMATION ABOUT AUTHORS}

Kazankov, Sergey P.. | E-mail: sergeykazankov@mail.ru

Cand. Sc. (Jurisprudence), Associate Professor

(C) Kazankov S. P., 2021

This is an open access article under the CC BY license (https://creativecommons.org/licenses/by/4.0/) 


\title{
Конституционные поправки \\ и пересмотр Конституции РФ: \\ особенности процедуры 2020 года
}

\author{
С. П. Казанков ${ }^{1}$
}

${ }^{1}$ Ярославский государственный университет им. П. Г. Демидова, ул. Советская, 14, Ярославль, 150003, Российская Федерация

DOI: $10.18255 / 1996-5648-2021-2-232-241$

УДК 342.4

Научная статья

Полный текст на русском языке

В статье рассматривается вопрос о порядке изменения Конституции Российской Федерации. Приводятся примеры норм иностранных конституций, которые конституционалисты признают жёсткими конституциями по порядку их изменения. Проанализированы способы изменения Конституции РФ: пересмотр, принятие поправок, изменение ст. 65. Особое внимание уделено процедуре принятия поправок к Конституции РФ. Выявлены такие проблемы, как форма поправки к Конституции, момент вступления поправки в силу, введение Законом РФ о поправке к Конституции РФ 2020 г. общероссийского голосования как дополнительного условия вступления поправки в силу, а также дополнительных полномочий Конституционного Суда РФ по проверке соответствия главам 1, 2 и 9 Конституции РФ положений Закона РФ о поправке к Конституции РФ, не вступивших в силу, а также порядка вступления в силу ст. 1 Закона о поправке. Высказываются соответствующие критические замечания. В частности, автор приходит к выводу, что одобрение конституционной поправки парламентами субъектов РФ является не моментом, а условием вступления в её в силу. Следовательно, закон о поправке не может вводить дополнительных условий вступления в силу конституционных поправок, поскольку это ведёт к нарушению требований ст. 136 Конституции, которые не могут быть изменены федеральным парламентом в порядке, предусмотренном главой 9 Конституции.

Ключевые слова: пересмотр Конституции; принятие поправки к Конституции; закон о поправке

ИНФОРМАЦИЯ ОБ АВТОРАХ

Казанков, Сергей Петрович $\quad$ E-mail: sergeykazankov@mail.ru

Кандидат юридических наук, доцент

Совершенно очевидно для доктрины, законотворчества и правоприменения, что изменение нормы конституции любого государства как ее основного закона влечёт за собой модификацию целой цепочки норм различного (C) Казанков С. П., 2021

Статья открытого доступа под лицензией CC BY (https://creativecommons.org/licenses/by/4.0/) 
Казанков С. П.

уровня и формирование новой практики её реализации. Этот процесс может быть достаточно длительным - до момента, пока сформируется практика реализации новых конституционных норм. А это порождает ситуацию длительной правовой неопределённости в регулировании общественного отношения. Понимание этого явственным образом подтверждает необходимость ее стабильности как основного закона и достаточно осторожного подхода при решении вопроса о возможности её изменения, тем более изменения значительного.

Требование стабильности обусловливает то, что многие современные конституции являются жёсткими - предусматривают более сложный порядок их изменения по сравнению с обычными законами, с тем чтобы сиюминутные политические интересы (например, стремление продлить срок полномочий государственного органа, расширить его компетенцию, перераспределить полномочия между органами государственной власти, нарушив баланс между ними, и т. д.) не могли реализовываться без одобрения большей частью общества, нежели простое представительное большинство. Для этих целей предусматривается либо проведение референдума, что соответствует учредительному характеру конституции, либо принятие документа представительным органом (в качестве такового может выступать регулярный парламент или специально созванный орган собрание, конвент), как правило, квалифицированным большинством голосов его членов. $К$ таковым можно отнести конституции Франции, ФРГ, Италии, КНР, Бразилии [1, с. 310, 437, 537, 750, 1046].

Так, например, для изменения французской конституции предусмотрены два этапа: принятие поправок и их одобрение на референдуме либо принятие их Парламентом, созываемым в формате Конгресса (ст. 89 Конституции Франции 1958 г.)‥ Согласно ст. 79 (2) Основного Закона $Ф Р \Gamma^{2}$ порядок его изменения не слишком сложный, тем не менее любой закон о поправке принимается двумя третями членов Бундестага и двумя третями голосов членов Бундесрата. Достаточно непросто изменить итальянскую Конституцию: её ст. 138 предусматривает, что законы, вносящие поправки в Конституцию и другие конституционные законы, должны обсуждаться палатами дважды; во время второго обсуждения одобрение закона осуществляется абсолютным большинством голосов; если в течение трёх месяцев после их опубликования одна пятая членов Палаты или пятьсот тысяч избирателей или пять областных советов сделают запрос о необходимости проведения референдума, то рассматриваемые законы выносятся на референдум

${ }^{1}$ Конституция Французской Республики 1958 г. // Конституционный Совет Французской Республики. URL: https://www.conseil-constitutionnel.fr/le-bloc-de-constitutionnalite/ texte-integral-de-la-constitution-du-4-octobre-1958-en-vigueur(дата обращения: 23.02.2021).

${ }^{2}$ Основной Закон Федеративной Республики Германии 1949 г. // Федеральный Конституционный Суд Федеративной Республики Германии. URL: https:/www.gesetze-im-internet. de/englisch_gg/englisch_gg.html\#p0414 (дата обращения: 23.02.202). 
и принимаются большинством голосов. Только после соблюдения означенной процедуры следует их официальное опубликование ${ }^{3}$.

Конституция США (ст. V) также является одной из самых жёстких в мире [2, с. 56]. Проект поправок к ней оформляется в виде объединённой резолюции, для принятия которой необходимо одобрение либо двумя третями голосов членов Сената и двумя третями голосов членов Палаты представителей Конгресса США, либо, если такое требование выдвинут легислатуры двух третей штатов, - специальным Конвентом. После этого следует процедура ратификации проекта поправок легислатурами трёх четвертей штатов либо конвентами трёх четвертей штатов. Одобрение поправок штатами завершает процедуру. На практике применялся первый вариант. Только для принятия XXI поправки был использован второй способ. История соответствующих конституционных поправок и их немногочисленность явным образом подтверждают крайне осторожное отношение американского политического истеблишмента к изменению основного закона своей страны.

К жестким относится и Конституция Российской Федерации 1993 года. Порядок её пересмотра, принятия поправок и изменения определён главой 9, которая относится к одной из трёх «защищённых» глав (наряду с главами 1 и 2) и, согласно ч. 1 ст. 135, ни при каких обстоятельствах не может быть пересмотрена фредеральным парламентом. Последний может лишь поддержать предложение о пересмотре положений глав 1, 2 и 9 квалифицированным большинством (тремя пятыми голосов от общего числа сенаторов и депутатов Государственной Думы), что становится основанием для созыва Конституционного Собрания в соответствии с федеральным конституционным законом, который до сих пор не принят. При этом Конституционное Собрание не изменяет главы 1,2 и 9, а обладает двумя полномочиями: 1) подтвердить неизменность Конституции РФ, 2) разработать проект новой Конституции. В случае принятия второго решения проект принимается либо самим Конституционным Собранием двумя третями голосов от общего числа его членов, либо всенародным голосованием. Конституция не предусматривает возможности изменения раздела II, касающегося вопросов перехода от прежней конституции к новой, а также преамбулы. Таким образом, глава 9 допускает принятие поправок к главам 3-8 Конституции (ст. 136) и изменение её статьи 65, которая определяет состав РФ. Изменения в ст. 65 вносятся федеральным конституционным законом (далее - ФКЗ); если в состав РФ принимается и в составе РФ образуется новый субъект Федерации, изменяется конституционно-правовой статус субъекта. В слу-

${ }^{3}$ Конституция Итальянской Республики 1947 г. // Конституционный Суд Итальянской Республики. URL: https:/www.cortecostituzionale.it/documenti/download/pdf/The Constitution_of_the_Italian_Republic.pdf (дата обращения: 23.02.2021). 
чае когда изменяется наименование субъекта РФ, новое наименование вводится в статью указом Президента РФ (ст. 137).

В 1998 г. был принят Федеральный закон от 04.03.1998 № 33-ФЗ «О порядке принятия и вступления в силу поправок к Конституции Российской Федерации» ${ }^{5}$ (далее - ФЗ 1998 г.), предметом правового регулирования которого стали порядок и условия внесения, принятия, одобрения и вступления в силу поправок к главам 3-8 Конституции Российской Федерации, а также порядок внесения изменений в её статью 65. Можно предположить, что столь сложная процедура для конституционных поправок, к тому же дифрференцированная в зависимости от их содержания, была обусловлена как объективными (соображения о необходимости стабильности конституционной основы российской государственности), так и субъективными причинами (в том числе ориентацией в означенный период времени на те или иные западные конституционные образцы). Однако с этой процедурой необходимо считаться. Если политические задачи и ориентации существенно меняются, ситуация в стране требует реформирования основного закона, следует предельно корректно, пусть и более затратно по времени и энергетике, осуществлять организацию соответствующего процесса.

Остановимся более подробно на порядке принятия поправок к главам 3-8, поскольку процедура принятия поправок в 2020 году, определённая Законом РФ о поправке к Конституции РФ от 14.03.2020 № 1-ФКЗ «О совершенствовании регулирования отдельных вопросов организации и фрункционирования публичной власти» ${ }^{6}$ (далее - Закон о поправке 2020 г.), подверглась некоторым изменениям, в связи с чем данный вопрос приобрёл ещё большую актуальность. Как справедливо отмечается в доктрине, в процедуре принятия поправок к Конституции можно обнаружить элементы, введённые ad hoc, без достаточно веских оснований; данное решение «оставляет на представлениях об учредительной власти отпечаток чрезвычайного характера» [3, с. 14].

Как мы установили ранее, ст. 136 Конституции определяет порядок принятия поправок к её главам 3-9. Во-первых, этот порядок должен быть аналогичным порядку принятия ФКЗ. Во-вторых, для вступления поправок в силу требуется их одобрение парламентами минимум двух третей субъектов Российской Федерации. Федеральный закон 1998 г. раскрывает

${ }^{4}$ Постановление Конституционного Суда РФ от 28.11.1995 № 15-П «По делу о толковании части 2 статьи 137 Конституции Российской Федерации» // Собрание законодательства РФ. 1995. № 49, ст. 4868.

${ }^{5}$ Федеральный закон от 04.03.1998 № 33-ФЗ (ред. от 08.03.2015) «О порядке принятия и вступления в силу поправок к Конституции Российской Федерации» // Российская газета. 1998. 10 марта.

${ }^{6}$ Закон РФ о поправке к Конституции РФ от 14.03.2020 № 1-ФКЗ «О совершенствовании регулирования отдельных вопросов организации и функционирования публичной власти». URL: http://www.pravo.gov.ru (дата обращения: 14.03.2020). 
понятие поправки - это любое изменение текста глав 3-8: исключение, дополнение, новая редакция любого положения названных глав.

Поправки принимаются в фрорме закона РФ о поправке к Конституции РФ. Следует отметить, что последняя не предусматривает такой вид закона. В связи с неопределенностью в понимании ст. 136 Конституции по запросу Государственной Думы Конституционный Суд РФ дал её толкование в части определения наименования и правовой формы документа, которым оформляется поправка к Конституции. Суд обнаружил наличие пробела в ст. 136, поскольку она не называет документ, которым вносятся конституционные поправки. Норма о том, что поправка принимается в порядке, предусмотренном для принятия ФКЗ, не означает, что этим документом должен быть именно ФКЗ. И Суд обосновал данное предположение: ФКЗ принимается во исполнение Конституции, на основе её бланкетных норм, то есть в случаях, прямо ею предусмотренных, поэтому использование документа означенной формы привело бы к невозможности внести поправки в Конституцию, поскольку поправка изменяет Основной закон, становится его частью, что нельзя сказать о ФКЗ. Конституционный Суд пришёл к выводу, что поправка должна вноситься специальным правовым актом о конституционной поправке, который имеет особый статус и отличается от уже имеющихся видов законов. Так, в порядке официального толкования Конституционным Судом ст. 136 Конституции РФ в России «появился» четвёртый вид закона - закон Российской Федерации о поправке к Конституции Российской Федерации (далее - закон РФ о поправке) ${ }^{7}$. При этом, как отмечает Н. Е. Таева, Суд выделил его специальные юридические свойства: 1) особый порядок принятия; 2) особая юридическая сила; 3) особый предмет правового регулирования [4, с. 45]. Важное значение для нашего исследования будет иметь особый предмет правового регулирования данного закона, представление о котором со временем подверглось изменению в практике Конституционного Суда РФ. Позиция Суда была отражена в ФЗ 1998 г., который подробно урегулировал порядок принятия закона РФ о поправке.

Следует обратить внимание на то, что согласно ст. 136 Конституции РФ поправки вступают в силу после их одобрения парламентами минимум двух третей субъектов РФ. Такая же формулировка содержится в Постановлении Конституционного Суда РФ 1995 г. Это даёт основание некоторым учёным полагать, что закон о поправке вступает в силу сразу после установления Советом Федерации результатов рассмотрения закона о поправке субъектами РФ (вынесения постановления об этом) [5, с. 19; 6, с. 18]. В то же время, как следует из ФЗ 1998 г., Государственная Дума «одо-

${ }^{7}$ Постановление Конституционного Суда РФ от 31.10.1995 № 12-П «По делу о толковании статьи 136 Конституции Российской Федерации» // Собрание законодательства РФ. 1995. № 45, ст. 4408 (далее - постановление КС РФ 1995 г.). 
Казанков С. П.

бряет» проект закона РФ о поправке (ст. 5), в Совете Федерации закон РФ о поправке «считается принятым» (ст. 6), Председатель Совета Федерации в соответствии с предписаниями ст. 7 и 8 публикует и направляет для рассмотрения в парламенты субъектов РФ уже закон РФ о поправке. Вступает в силу закон со дня его официального опубликования Президентом РФ после установления результатов рассмотрения субъектами РФ (ст. 13). При этом следует обратить внимание, что в самих ранее принятых законах РФ о поправке указывается об «одобрении» их палатами российского парламента. Имеет место несоответствие формулировок законов о поправке терминологии ФЗ 1998 г. Тем не менее очевидно, что в данном случае одобрение поправки не менее чем двумя третями субъектов РФ является не моментом, а условием вступления поправки в силу.

В чём состоят особенности процедуры, определённые Законом РФ о поправке 2020 года? Собственно поправки в Конституцию содержатся в ст. 1 указанного закона, который был принят в соответствии с порядком, установленным ст. 136 Конституции РФ и ФЗ 1998 г.: 11 марта 2020 г. одобрен Государственной Думой и Советом Федерации Федерального Собрания РФ, 14 марта Совет Федерации установил, что 85 субъектов РФ рассмотрели и одобрили Закон РФ о поправке и постановил направить закон Президенту РФ для подписания и обнародования ${ }^{8}$. В тот же день 14 марта 2020 г. Президент РФ, как это предусмотрено п. 2 ст. 12 ФЗ 1998 г., подписал и обнародовал данный закон (на Официальном интернет-портале правовой информации http://www.pravo.gov.ru), который сразу вступил в силу. Воистину данный скоростной режим впечатляет...

Следует заметить, что 14 марта 2020 г. вступили в силу не поправки к Конституции РФ (статья 1), а нормы ст. 3, которые определяют порядок вступления в силу статьи 1 , по существу наделяющие Конституционный Суд РФ новыми полномочиями проверить соответствие положениям глав 1, 2 и 9 Конституции РФ положений данного Закона, которые не вступили в силу, а также о соответствии Конституции порядка вступления в силу статьи 1 Закона. В случае положительного заключения Конституционного Суда должна была вступить в силу ст. 2 Закона о поправке, которая содержит нормы избирательного права, регулирующие порядок проведения всероссийского голосования, назначаемого по инициативе Президента РФ и указом Президента РФ (ч. 2 ст. 2). 16 марта 2020 г. такое заключение Конституционным Судом было дано. Суд установил, что процедура принятия закона о поправке, предусмотренная ст. 136 Конституции, соблюдена,

${ }^{8}$ Постановление Совета Федерации Федерального Собрания РФ от 14.03.2020 № 98СФ «Об установлении результатов рассмотрения законодательными (представительными) органами государственной власти субъектов Российской Федерации Закона Российской Федерации о поправке к Конституции Российской Федерации «О совершенствовании регулирования отдельных вопросов организации и функционирования публичной власти». URL: http://www.pravo.gov.ru (дата обращения: 14.03.2020). 
с чем трудно не согласиться. Конституционный Суд данной нормой не указан в качестве субъекта, участвующего в процедуре изменения Конституции, однако признал своё участие допустимым по двум причинам: во-первых, Суд выступает в данном случае гарантом защиты норм об основах конституционного строя и важнейших прав и свобод человека; во-вторых, он обеспечивает непротиворечивость текста Конституции ${ }^{9}$.

Конституционный Суд признал своё право осуществлять предварительный конституционный контроль положений закона РФ о поправке, не вступивших в силу (абз. 4, 5 п. 2 Заключения). Он также указал, что не оценивает, насколько согласованны нормы Закона РФ о поправке 2020 г. и ФЗ 1998 г. в части вступления в силу конституционных поправок со дня опубликования результатов голосования при условии, если такие поправки будут одобрены. При этом Суд отметил, что Закон 2020 г. в части процедуры является правовым актом специальным и более новым, обладающим большей юридической силой. В этой связи согласимся с мнением Н. Е. Таевой, которая полагает, что не следует рассматривать Закон 1998 г. и Закон о поправке 2020 г. как общий и специальный; между ними недопустимо установление соотношения по юридической силе в зависимости от времени принятия, поскольку данные акты имеют разный предмет правового регулирования [4, с. $51 ; 7]$.

Что касается введённого Законом 2020 г. всероссийского голосования как условия вступления в силу поправок, Конституционный Суд заключил, что проведение голосования, не предусмотренного действующими нормами права, допустимо. При этом определил возможную цель такого нововведения - конституционная легитимация решения законодателя, а также принцип народовластия, которым законодатель руководствовался при принятии данного решения (абз. 5 п. 2.1 Заключения). В доктрине отмечается, что проведённое в 2020 г. голосование имеет особую юридическую природу, не является рефререндумом или общественным обсуждением проектов законов, преследует цель дополнительной легитимации изменений Конституции [8, с. 70].

Однако следует отметить, что в п. 185 Доклада о конституционных поправках (CDL-AD (2010) 001) указано: референдумы должны использоваться, если это соответствует конституционному строю государства в целом, они не должны проводиться, если это прямо не предусмотрено конститу-

${ }_{9}^{9}$ Заключение Конституционного Суда РФ от 16.03.2020 № 1-3 «О соответствии положениям глав 1,2 и 9 Конституции Российской Федерации не вступивших в силу положений Закона Российской Федерации о поправке к Конституции Российской Федерации «О совершенствовании регулирования отдельных вопросов организации и функционирования публичной власти», а также о соответствии Конституции Российской Федерации порядка вступления в силу статьи 1 данного Закона в связи с запросом Президента Российской Федерации». URL: http://www.pravo.gov.ru (дата обращения: 16.03.2020). 
Казанков С. П.

цие ${ }^{10}$. Несмотря на то что проведённое голосование референдумом не является, его вряд ли следовало проводить без прямого указания на то в Конституции РФ. Вызывает сомнение и введение всероссийского голосования в обход уже существующих норм избирательного права. Впрочем, в контексте поставленных политических задач это, конечно, имеет вполне очевидное объяснение.

Таким образом, закон о поправке, который был принят в соответствии с главой 9 Конституции, не вносил изменения в Конституцию. После принятия в соответствии с данной процедурой «активировались» положения этого Закона, содержащие нормы избирательного права, а также касающиеся полномочий Конституционного Суда РФ. Вместе с тем нелишне подчеркнуть, что любой нормативный правовой акт имеет предмет своего правового регулирования, который может быть заранее определён конституцией или законом. Например, федеральные законы могут приниматься как в случаях, прямо указанных в Конституции РФ, так и в иных случаях, если вопрос относится к ведению федеральных органов государственной власти или совместному ведению РФ и субъектов РФ в соответствии со ст. 1 и 72 Конституции РФ. Федеральные конституционные законы, как уже было отмечено выше, принимаются в случае наличия бланкетной нормы Конституции, то есть когда это прямо Конституцией предусмотрено. Правда, имела место практика, согласно которой ФКЗ принимаются и по иным вопросам, когда необходимо соответствующим нормам придать более высокую юридическую силу.

В любом случае и федеральные, и федеральные конституционные законы предусмотрены в качестве видов законов РФ действующей Конституцией. Этого нельзя сказать о законе РФ о поправке. Данный вид закона, как мы установили, не был предусмотрен Конституцией, а был «выведен» Конституционным Судом РФ в порядке толкования. В Конституции РФ имелся пробел, который был Судом восполнен. В названии закона указан и предмет его правового регулирования - поправка к Конституции. Не порядок внесения поправки, а именно норма, которая вносится в Конституцию, а закон выступает в качестве формы внешнего выражения этой нормы. Не может быть предметом правового регулирования закона РФ о поправке порядок принятия поправки, поскольку это предмет правового регулирования «защищённой» от изменений главы 9. В определении от $17.07 .2014^{11}$ Конституционный Суд допустил, что закон РФ о поправке может содер-

10 Доклад о конституционных поправках (CDL-AD (2010) 001), принятый Венецианской комиссией на 81-м пленарном заседании (Венеция, 11-12 декабря 2009 г.). URL: https://www. venice.coe.int/webforms/documents/default.aspx?pdffile $=\mathrm{CDL}-\mathrm{AD}(2010) 001$-rus $\quad$ (дата обращения: 11.02.2021).

${ }^{11}$ Определение Конституционного Суда РФ от 17.07.2014 № 1567-О «По запросу группы депутатов Государственной Думы о проверке конституционности ряда положений Закона Российской Федерации о поправке к Конституции Российской Федерации «О Верхов- 
жать «положения переходного характера», которые не включаются в текст Конституции. Однако положения, наделяющие Конституционный Суд новыми полномочиями, а также вводящие избирательные процедуры и дополнительные для вступления поправок в силу условия, вряд ли можно признать положениями переходного характера. По нашему мнению, эти положения не соответствуют требованию 136 Конституции РФ о том, что поправки вступают в силу после того, как будут одобрены парламентами двух третей субъектов РФ, и, по сути, изменяют положения главы 9 Конституции, что вряд ли можно признать допустимым. Полагаем, что проанализированные нами и темпоральная, и сущностная составляющие деятельности по реформированию даже той части конституционных основ, которые в принципе могли быть подвергнуты изменению, нуждаются в более тонкой настройке. Процесс (перефразируя известную фрормулу доктрины), возможно, не всегда является «фрормой жизни материального закона», однако даже некоторое пренебрежение процедурой чревато повторением аналогичного пренебрежения в будущем. И если будущее нас интересует, то мы должны иметь это в виду.

ном Суде Российской Федерации и прокуратуре Российской Федерации». URL: http://www. pravo.gov.ru ( дата обращения: 22.07.2014).

\section{Ссылки}

1. Конституционное (государственное) право зарубежных стран. Особенная часть: учебник / отв. ред. Б. А. Страшун. М.: Норма, 2008. 1136 с.

2. Шумилов В. М. Правовая система США. М.: Международные отношения, 2006. 408 c.

3. Джагарян А. А. Исправленному верить? Субъективные заметки в связи с Заключением Конституционного Суда РФ от 16 марта 2020 г. № 1-3 // Конституционное и муниципальное право. 2020. № 8. С. 9-17.

4. ТаеваН.Е.ЗаконРоссийскойФедерацииопоправкекКонституцииРоссийской Федерации: эволюция юридических свойств // Актуальные проблемы российского права. 2020. № 8. С. 43-54.

5. Тарибо Е. В. Судебный конституционный нормоконтроль: осмысление российского опыта: монография. М.: Норма, 2018. 256 с.

6. Евдокимов В. Б., Тухватуллин Т. А. Некоторые проблемы внесения поправок в Конституцию Российской Федерации (теория и практика) // Государственная власть и местное самоуправление. 2014. № 4. С. 15-19.

7. ТаеваН.Е.ЗаконРоссийскойФедерацииопоправкекКонституцииРоссийской Федерации: эволюция юридических свойств // Государство и право. 2021. № 2. С. 7-15.

8. Хабриева Т.Я., Клишас А. А. Тематический комментарийк Закону Российской Федерации о поправке к Конституции Российской Федерации от 14 марта 2020 г. № 1-ФКЗ «О совершенствовании регулирования отдельных вопросов организации и фрункционирования публичной власти». М.: Норма, ИНФРА-М, 2020. 240 с. 